\title{
Editorial
}

\section{Prevention of Hepatocellular Carcinoma}

\author{
Ryota Masuzaki ${ }^{1}$ and Masao Omata ${ }^{2}$
}

Hepatocellular carcinoma (HCC) is the fifth common cancer in the world, showing the third highest cancer related mortality. The prognosis of HCC patients depends not only on tumor stage but also on the background liver function reservoir. Effective treatments for HCC include percutaneous ablation, surgical resection and liver transplantation. Although short-term prognosis of HCC patients has been much improved recently due to advances in early diagnosis and treatment, long-term prognosis is as yet far from satisfactory as indicated by the overall survival at 10 years after apparently curative treatment of only $22 \%-35 \%$.

Primary prevention aims to evade the tumor development with health measures that prevent people from exposure to known risk factors like hepatitis viruses or alcohol, or attenuating liver disease progression to HCC. While secondary prevention aims to diagnose $\mathrm{HCC}$ at an early, potentially curable stage, tertiary prevention aims to reduce the risk of HCC recurrence after curative treatment. In this article we focus on prevention of HCC and the new advance in this field.

Key words: Prevention; Hepatocellular carcinoma; Treatment; Radiofrequency ablation

$\mathrm{H}$ epatocellular carcinoma (HCC), one of the most common cancers worldwide, usually develops in patients with livers that are already chronically damaged, often from cirrhosis. ${ }^{1}$ The etiology of liver disease and consequently that of HCC, differs geographically. In most areas, chronic viral hepatitis, resulting from infection with either the hepatitis $\mathrm{B}$ virus (HBV) or the hepatitis $\mathrm{C}$ virus (HCV), is the main cause of $\mathrm{HCC}^{2-5} \mathrm{HCC}$ is also associated with lifestyle factors. Chronic alcoholism is a classic risk factor for the development of HCC and obesity is also recognized to strongly affect HCC development, along with the development of other malignancies. ${ }^{6}$

$\mathrm{HCV}$ infection has rapidly expanded worldwide in recent years. ${ }^{7} \mathrm{HCV}$ is transmitted from person to person as a blood-borne infection, although it is much less infectious than HBV. Mother-neonate transmission and horizontal sexual transmission are uncommon with HCV. Therefore, the recent rapid spread of HCV must be associated with some artificial change in the environment. Epidemiological studies have shown that the spread of the virus began in the United States in the mid 1960s, primarily among intravenous drug users. The rate of $\mathrm{HCV}$ infections then began to decline by the 1990 s, when general concern regarding human immunodeficiency virus (HIV) infection increased substantially.

In the United States, the transmission route of $\mathrm{HCV}$ overlapped that of HIV. This led to a serious medical problem, HCV/HIV co-infection, in which liver

\footnotetext{
${ }^{1}$ Department of Surgery, Division of Liver Transplantation Vanderbilt University; ${ }^{2}$ Department of Gastroenterology, Yamanashi Central and Kita Hospitals, University of Tokyo

Correspondence: Masao Omata,Yamanashi Prefectural Hospital Organization Fujimi, Kofu, Yamanashi, Japan, 400-8506; E-mail:momata-tky@umin.ac.jp
}

damage progresses more rapidly due to comorbid immunosuppression. Currently, approximately onetenth of all patients with HCV infection in the United States are also infected with HIV. With improved treatments for HIV having reduced the mortality of that disease, HCV-related disease is currently the primary cause of mortality in patients with $\mathrm{HIV} / \mathrm{HCV}$ coinfection. ${ }^{8}$ In contrast, in Egypt, where the prevalence of HCV infection is estimated to be $10 \%$ or higher, the virus is thought to be transmitted via a peculiar iatrogenic route in which parenteral antischistosomal therapy is administered to patients using serum from infected donors, which was widely practiced from the 1960 s to the early 1980 s. $^{9}$ This resulted in the predominance of $\mathrm{HCV}$ genotype $4 \mathrm{a}$, which is unique to Egypt.

In Japan, HCC-related mortality has more than tripled since the mid 1970s. At that time, emerging cases of HCC developed in patients who were typically negative for HBV and who were diagnosed with so-called non-A non-B hepatitis, which was later revealed to be almost entirely the same as chronic hepatitis C. ${ }^{10}$ Presently, $\mathrm{HCV}$ infection is responsible for $75 \%$ to $80 \%$ of cases of HCC in Japan, while HBV is responsible for $10 \%$ to $15 \%$ of cases. ${ }^{11}$ Approximately $40 \%$ of HCV-related HCC patients in Japan have a history of receiving blood transfusions, usually during the 1950s and 1960s. At that time, the supply of blood used for transfusion in Japan was obtained from paid blood donors, many of whom were also intravenous drug users, primarily of methamphetamine, and among whom HCV is thought to have spread first in Japan after the end of World War II . In addition, the routine reuse of syringes and needles in medical practice at that time may have contributed to further spread of the virus. Commercial 
blood banks were abolished by 1969 in Japan and were replaced by the Japanese Red Cross Society, which is fully dependent upon voluntary blood donations to meet its blood supply needs. Syringe and needle reuse was also strongly discouraged in the 1970s. Consequently, the spread of HCV in Japan began to decline in the 1970s, although the transmission of $\mathrm{HCV}$ through blood transfusions continued until the advent of a sensitive HCV detection system in the early 1990s. In Japan, there was an interval of at least 30 years between the peak of the spread of HCV and the peak incidence of HCV-related HCC. Considering the interval of 20 years between the peak of the spread of the virus in Japan versus the United States and the fact that it takes 20 years or longer for HCC to develop after $\mathrm{HCV}$ infection, a further increase in the incidence of HCC in the United States appears to be inevitable. ${ }^{12,13}$

\section{PREVENTION OF HCC}

$\mathrm{HCC}$ is a unique malignancy in that known acquired factors (i.e., chronic viral hepatitis B and C) are the predominant causes of carcinogenesis, which is of enormous clinical importance (Table 1). ${ }^{14,15}$ By screening for $\mathrm{HBV} / \mathrm{HCV}$ infection, we can identify patients at high risk of developing $\mathrm{HCC}$ and achieve cost-effective surveillance. Screening policies should be based on the prevalence of each viral infection in specific geographic areas. This will result in secondary prevention of HCC through early detection and treatment. Furthermore, primary prevention of HCC (i.e., reducing risk factors) is possible by controlling the spread of virus infections. In fact, HBV vaccination has been shown to be effective in decreasing HBVrelated $\mathrm{HCC}$, and awareness among both medical practitioners and the general population of the methods used to control the spread of blood-borne infections has apparently curbed further increases in the number of HCV infections.

The primary prevention of $\mathrm{HCV}$-related $\mathrm{HCC}$ includes strategies for the prevention of $\mathrm{HCV}$ infection and for viral eradication. Regarding the former, novel HCV transmission in the general population has been declining in many countries, as evidenced by the lower prevalence of HCV infection among younger generations. Viral transmission through blood transfusions can be prevented by screening donor blood using sensitive assays. Although campaigns warning against actions that lead to blood-borne viral transmission, including that of both $\mathrm{HCV}$ and HIV, should be sustained vigorously, effort can now be focused on viral eradication in patients who have already been infected with HCV.

The effect of IFN therapy on the prevention of HCC is controversial. Recently, a large-scale RCT, called the Hepatitis C Antiviral Long-Term Treatment Against Cirrhosis (HALT-C) study, was performed in the USA. No significant difference in the incidence of HCC was seen between patients assigned to receive peginterferon alfa-2a $90 \mu \mathrm{g} /$ week as maintenance therapy $(\mathrm{n}=495)$ and those assigned to receive no treatment $(n=510) .{ }^{16}$ The cumulative incidence of HCC after randomization was almost identical in the two groups: $5.4 \%$ in the treatment group and $5.0 \%$ in the control group. In contrast, many clinical studies performed in Japan have clearly demonstrated that the incidence of HCC is reduced among IFN-treated patients showing a sustained virologic response. ${ }^{17,18}$ The resolution of cirrhosis is also noted following a sustained virologic response. ${ }^{19}$ These beneficial effects are expected to be enhanced by the advent of combined pegylated-IFN and ribavirin therapy. ${ }^{20,21}$ The discrepancy between the Japanese and American studies regarding the preventive effect of IFN therapy on HCC may result from different patient characteristics, such as the ages of the HCV-infected patients. Further investigation is therefore required.

\section{Target populations}

In Japan, $\mathrm{HCV}$ infection is responsible for approximately $80 \%$ of all cases of HCC, whereas HBV infection is responsible for $10 \%$ of cases of $\mathrm{HCC}$ and alcohol for approximately $5 \%$ of cases of $\mathrm{HCC}^{22,23}$ These values may differ substantially in other countries. For example, in China, where the prevalence of HBV infection is much higher, HBV infection is by far the predominant etiologic factor for the development HCC.

Given the low incidence of $\mathrm{HCC}$ in individuals without risk factors, surveillance is not recommended for the general population. A commonly accepted rate of infection that requires surveillance is greater than $0.2 \%$ per year. Therefore, the first step in screening for $\mathrm{HCC}$ is to screen patients at risk of developing HCC. Because chronic viral hepatitis that results from either HBV or HCV may be asymptomatic, mass screening for hepatitis infection, either $\mathrm{HBV}$ or $\mathrm{HCV}$, is justified if the prevalence of infection in a region is reasonably

Table 1. Strategies for Prevention of HCC

\begin{tabular}{|c|c|c|}
\hline Virus & Hepatitis B & Hepatitis C \\
\hline New infection & Neonate vaccination & General Infection Control \\
\hline Existing infection & $\begin{array}{l}\text { Antiviral therapy (Supression) } \\
\text { Nucleos(t)ide analogs }\end{array}$ & $\begin{array}{l}\text { Antiviral therapy (Eradication) } \\
\text { Interferon, Ribavirin, DAAs }\end{array}$ \\
\hline Treatment & \multicolumn{2}{|c|}{$\begin{array}{l}\text { Early diagnosis and curative treatment } \\
\text { Transplantation }\end{array}$} \\
\hline Recurrence & \multicolumn{2}{|c|}{ Antiviral therapy } \\
\hline
\end{tabular}


high. Indeed, in Japan, the general population over 40 years of age has undergone mass screening for HBV and HCV infections since 2002, although the costeffectiveness of this program remains to be evaluated.

Persistent HBV infection is a major risk factor for the development of HCC. HBV carriers have a 223 -fold higher risk of developing $\mathrm{HCC}$ than non-carriers. ${ }^{24}$ Among HBV carriers, HBe antigen-positive patients are at a higher risk of developing $\mathrm{HCC}$ than $\mathrm{HBe}$ antigen-negative patients (relative risk, 6.3 -fold). ${ }^{25,26}$ Recently, the results of a large-scale, long-term cohort study conducted in Taiwan showed that the level of serum HBV DNA is the strongest predictor of both progression to cirrhosis and development of HCC among HBV-positive patients, independently of the patient's serum HBe antigen/antibody status or ALT levels. ${ }^{27}$ Together with the advent of reliable quantitative assays, the determination of a patient's HBV DNA levels may replace determination of $\mathrm{HBe}$ antigen/antibody status as a risk indicator for HCC.

While the prevalence of chronic HBV infection is high in some geographic areas, such as East and Southeast Asia and sub-Saharan Africa, the prevalence of chronic HCV infection has recently increased in some developed countries, including Japan, southern European countries, and the United States. In patients with chronic hepatitis $\mathrm{C}$, the risk of developing HCC increases with progression of liver fibrosis, ${ }^{17,28}$ and chronic hepatitis $\mathrm{C}$ patients with cirrhosis have a very high risk of developing HCC. ${ }^{29}$ In Japan, HCV infection spread nationally primarily in the 1950's and 1960's. Progression to cirrhosis requires several decades to occur, and HCV infection is now the predominant cause of HCC in Japan. Peak viral spread in the United States occurred two decades later, and the incidence of HCVrelated HCC is now increasing rapidly. ${ }^{2,30}$ In addition to the degree of liver fibrosis, male gender, older age, and heavy alcohol consumption are known risk factors for developing HCV-related HCC.

Cirrhosis due to etiologies other than chronic viral hepatitis also confers a risk of developing HCC. Major etiologies include alcoholic liver disease and $\mathrm{NASH},{ }^{31-33}$ whose relative importance may differ geographically. Hassan et al reported that alcoholic liver disease accounted for $32 \%$ of all HCC cases in an Austrian cohort. ${ }^{34}$ In the United States, the approximate annual hospitalization rate for $\mathrm{HCC}$ related to alcoholic cirrhosis is $8 / 100,00$ to $9 / 100,000$ compared to approximately $7 / 100,000$ for hepatitis $\mathrm{C} .{ }^{35} \mathrm{NASH}$ is a chronic liver disease that is gaining increasing significance due to its high prevalence worldwide and its potential for progression to cirrhosis, $\mathrm{HCC}$ and liver failure. Although NASH has been described in cohorts of HCC patients, ${ }^{36,37}$ the incidence of HCC in patients with cirrhosis due to NASH is unclear. Aflatoxin may play a role in certain areas.

In brief, accurately evaluating the degree of liver fibrosis is of paramount importance in assessing the risk of developing $\mathrm{HCC}$ in patients with chronic liver disease of any etiology. The histologic evaluation of liver biopsy samples has been considered the gold standard for assessing liver fibrosis. However, the invasiveness of a liver biopsy limits its clinical feasibility. In clinical practice, repeated assessment of liver fibrosis is often required because a non-cirrhotic liver may become cirrhotic over time, and sometimes rather rapidly. Consequently, the non-invasive evaluation of liver fibrosis is one of the main areas of interest in hepatology.

One such non-invasive method, transient elastography, correlates well with the histological stage of liver fibrosis. ${ }^{38-42}$ In transient elastography, shear waves are emitted into the liver and their velocity is measured with ultrasound. Since the velocity of the waves is directly correlated with the elasticity of the liver, liver stiffness, or the degree of fibrosis, can be non-invasively measured. The reported cut-off value for the diagnosis of histological cirrhosis is 12.5 to 14.9 $\mathrm{kPa}$. Higher values of liver stiffness may require proper attention regarding the potential for decompensation and HCC development. ${ }^{43,44}$ The FibroTest is based on the age and gender of the patient combined with five biochemical markers (total bilirubin, haptoglobin, $\gamma$-glutamyl transpeptidase, alpha-2 macroglobulin, and apolipoprotein $\mathrm{A} 1) .{ }^{45} \mathrm{An}$ index of 0 to 0.10 has a $100 \%$ negative predictive value, while an index of 0.60 to 1.00 has a greater than $90 \%$ positive predictive value for a Metavir score of F2 to F4. APRI is the aspartate aminotransferase (AST) level/upper limit of normal divided by the platelet count $\left(10^{9} / \mathrm{L}\right)$ multiplied by $100{ }^{46}$ For a hypothetical patient with an AST of $90 \mathrm{IU} / \mathrm{L}$ (upper limit of normal 45) and a platelet count of 100 $\left(\times 10^{9} / \mathrm{L}\right)$, the APRI is 2.0 , which means that the patient has a $41 \%$ likelihood of having advanced fibrosis and a $5 \%$ chance of having minimal or no fibrosis. The applicability of these methods in surveillance requires evaluation in future prospective studies.

\section{Surveillance methodology}

Traditionally, two methodologies have been used for HCC surveillance in high-risk patients: tumor marker determination and diagnostic imaging. Serum alphafetoprotein (AFP) concentration is representative of the former and liver ultrasonography (US) is representative of the latter. Although serum AFP measurements are generally less sensitive than US, their specificities may be comparable when using appropriate cut-off values. HCC screening via combined US and AFP may lead to improved detection, although previous reports have been generally negative. ${ }^{47-50}$ However, in a non-randomized study of patients with cirrhosis, the sensitivity of detection was reported to be increased using both US and AFP measurements, as compared to using either alone. ${ }^{48}$ 
Recently, a randomized trial evaluated the effectiveness of HCC screening using AFP and US every six months compared to no screening in over 18,000 Chinese patients with HBV infection. ${ }^{51}$ More cases of HCC were diagnosed in the screened group than in the non-screened group ( 86 vs. 67) and overall survival was higher in the screened group $(65.9 \%$, $52.6 \%$ and $46.4 \%$ at 1,3 , and 5 years, respectively) than in the non-screened group $(31.2 \%, 7.2 \%$ and $0 \%$ at 1,3 , and 5 years, respectively).

A retrospective study assessed the effectiveness of HCC screening in 367 patients of 70 years of age or older using AFP measurements and US every six or 12 months. The screening allowed for more frequent diagnoses of HCC at an early stage, increasing the proportion of patients who were able to receive a curative treatment, and improving the prognoses of these patients compared to that of the unscreened patients. The apparent survival benefit was restricted to the first 3 years after the detection of HCC, mostly likely because elderly people have a shorter life expectancy. ${ }^{52}$

\section{PREVENTION OF RECURRENCE}

Effective treatments for HCC include percutaneous ablation, surgical resection, and liver transplantation. Among these, image-guided percutaneous ablation is considered best for early-stage HCC. Survival rates of HCC patients grouped based on treatment modality, which was reported by the Liver Study Cancer Group of Japan, is shown in Table 2. Ethanol injection was formerly the standard procedure used among the various percutaneous ablation techniques. However, randomized control trials have demonstrated that radiofrequency ablation (RFA) has a more reliable local antitumor effect leading to higher survival rates. ${ }^{53,54} \mathrm{In}$ a recent study, Shiina et al. reported 10-year outcomes of RFA. ${ }^{55}$ They performed 2,982 RFA treatments on 1,170 primary HCC patients and analyzed the collected data. Complete tumor ablation was achieved in 2,964 $(99.4 \%)$ of 2,982 treatments. With a median follow-up of 38.2 months, the 5-year and 10-year survival rates were $60.2 \%$ and $27.3 \%$, respectively.

Ever since acceptable levels of safety in hepatectomy were archived, surgical resection has been considered to be the sole potentially curative treatment for HCC; however, hepatectomy currently competes with transplantation and percutaneous ablation for this designation. Resection is usually indicated in patients with solitary HCC and preserved liver function. Having poor liver function reservoir limits the extent of hepatic resection that can be performed. This poses no difficulty when HCC arises in a normal liver. However, since HCC usually develops in cirrhotic livers, the preoperative evaluation of liver function is essential. Anatomical resection is preferred by some surgeons, who perform segment-wise hepatectomy whenever possible. This is based on the idea that intrahepatic microscopic metastasis is likely to occur in the same segment as the original tumor via the portal vein. The survival rates for patients properly selected to receive surgical hepatectomy exceeds $70 \%$ at five years, although the overall survival rate is substantially reduced without strict selection of patients. ${ }^{56}$ Therefore, hepatectomy plays a limited role in the treatment of HCC. ${ }^{57}$ Only $20 \%$ to $30 \%$ of patients are good candidates for hepatectomy, with the other patients being contraindicated by either having liver function too impaired or having tumor stages too advanced. Most importantly, even after apparently curative surgical resections are performed, $80 \%$ of patients develop recurrent $\mathrm{HCC}$ within five years ${ }^{58}$ because of latent intrahepatic metastasis or metachronous multicentric carcinogenesis.

The restriction on hepatic resection posed by poor liver function reservoir can be lifted in cases of liver transplantation. Although extrahepatic comorbidity and old age can limit a patient's eligibility for transplantation, the status of patient's background liver will not be a contraindication, whatever the degree or

Table 2. Survivals of HCC patients according to the treatments (1992-2003)

\begin{tabular}{|c|c|c|c|c|c|c|c|c|}
\hline \multirow{2}{*}{ Treatment } & \multirow{2}{*}{ Number } & \multicolumn{3}{|c|}{ Survival (\%) } & \multirow{2}{*}{ Liver damage $^{\mathrm{a}}(n)$} & \multicolumn{3}{|c|}{ Survival (\%) } \\
\hline & & 1 year & 3 years & 5 years & & 1 year & 3 years & 5 years \\
\hline Resection & 27062 & 87.8 & 69.2 & 52.1 & $\begin{array}{l}\text { A (17433) } \\
\text { B (7260) } \\
C(631)\end{array}$ & $\begin{array}{l}89.9 \\
85.2 \\
74.1\end{array}$ & $\begin{array}{l}73.4 \\
59.4 \\
69.6\end{array}$ & $\begin{array}{l}58.4 \\
45.3 \\
35.5\end{array}$ \\
\hline RFA & $\begin{array}{l}5478 \\
(1998-2003)\end{array}$ & 94.9 & 76.7 & 57.3 & $\begin{array}{l}\mathrm{A}(2927) \\
\mathrm{B}(2123) \\
\mathrm{C}(277)\end{array}$ & $\begin{array}{l}97.1 \\
94.4 \\
80.7\end{array}$ & $\begin{array}{l}82.7 \\
72.2 \\
52.4\end{array}$ & $\begin{array}{l}73.6 \\
- \\
-\end{array}$ \\
\hline PEIT & 14726 & 91.3 & 63.0 & 39.4 & $\begin{array}{l}\text { A (7257) } \\
\text { B (5243) } \\
C(1237)\end{array}$ & $\begin{array}{l}94.7 \\
91.8 \\
76.8\end{array}$ & $\begin{array}{l}72.2 \\
57.7 \\
36.7\end{array}$ & $\begin{array}{l}48.4 \\
32.9 \\
19.2\end{array}$ \\
\hline TACE & 30490 & 74.5 & 40.2 & 21.3 & $\begin{array}{l}\text { A (11094) } \\
\text { B (8365) } \\
C(2303)\end{array}$ & $\begin{array}{l}83.7 \\
75.4 \\
56.8 \\
\end{array}$ & $\begin{array}{l}51.4 \\
37.5 \\
19.8 \\
\end{array}$ & $\begin{array}{r}29.8 \\
18.2 \\
7.0 \\
\end{array}$ \\
\hline
\end{tabular}

Note: ${ }^{a}$ The liver function classification reported by the Liver Cancer Study Group of Japan using the category indocyanine green retention rate at 15 $\min [\mathrm{ICG}(\mathrm{R} 15)]$ instead of encephalopathy in the Child-Pugh classification. 
severity of liver dysfunction, or whatever the degree or severity of the underlying cirrhosis. ${ }^{59,60}$ Indeed, the recovery of liver function is the chief object of liver transplantation performed for liver failure in patients without $\mathrm{HCC}$, and this is also applicable to patients with HCC. The restriction on resection posed by having a multiplicity of HCC lesions can also be overcome by liver transplantation when the restriction is due to the fact that the expected remnant liver volume is too small. Of course there is a certain limitation concerning the stage of the tumor, beyond which posttransplant HCC recurrence is likely to occur. Posttransplant $\mathrm{HCC}$ recurrence is usually of an aggressive nature and associated with a poor prognosis, most likely due to the use of immunosuppressants. Pretransplant tumor invasion into large vessels is a definite contraindication for transplantation. Currently the Milan criteria are widely accepted as indication criteria for liver transplantation in patients with HCC. These criteria are: a solitary tumor of $5 \mathrm{~cm}$ or less in diameter or three or fewer lesions each measuring $3 \mathrm{~cm}$ or less in diameter. ${ }^{60,61}$ However, the Milan criteria were not based on exhaustive evidence and there have been ceaseless efforts to extend the criteria. What is really needed is not a static anatomic description of the extent of HCC, but more sophisticated prognosticators of the behavior of an individual tumor, possibly obtainable through genomics or proteomics.

The short-term prognosis of patients with HCC has greatly improved due to recent advances in early diagnosis and treatment. However, long-term prognoses remain far from satisfactory, as indicated by the fact that the overall survival rates 10 years after apparently curative treatment of $\mathrm{HCC}$ are as low as $22 \%$ to $35 \%{ }^{62,63}$ In patients with HCC, the slope of a typical cumulative survival curve after treatment does not level out over time. In contrast, in most other malignancies, the slope of the cumulative survival curve levels out approximately five years after relatively curative treatments are performed. In other words, HCC is rarely treated curatively, and the primary reason for this is the frequent recurrence of HCC, even after apparently curative treatment involving either local ablation or surgical resection are performed.$^{64}$ Unlike liver transplantation, these locoregional therapies do not remove microscopic lesions from the remaining liver. However, this does not explain the fact, specific to HCC that the risk of recurrence does not decline over time. In fact, recurrent HCC continues to develop at an annual rate of $10 \%$ to $20 \%$. The continual recurrence of HCC after initial treatment is thought to be mostly due to multicentric de novo carcinogenesis. In this respect, liver transplantation is superior to locoregional therapy.

At least theoretically, however, strategies similar to those used in primary prevention may be applicable to HCC recurrence that results from multicentric carcinogenesis. Recent antiviral therapies, in particular, may be considered in this regard. HCV-related HCC patients have undergone IFN therapy after the initial treatment, which may have reduced the incidence of recurrence in these patients. ${ }^{65,66}$ Liver function did not deteriorate in patients who achieved a sustained virologic response with IFN therapy, among whom there were no occurrences of death due to liver failure. Consequently, overall survival rates improved in patients subjected to IFN therapy.

Needless to say, early diagnosis and complete removal of primary HCC lesions are requisites for antiviral therapy. Safe, effective chemotherapeutic agents would be useful as adjuvant therapy in relatively advanced cases of HCC where undetectable intrahepatic metastases are suspected. However, conventional chemotherapeutic agents are not satisfactorily effective against HCC, nor are they safe enough for protective long-term use. Hasegawa et al. ${ }^{67}$ reported that the administration of uracil-tegafur (UFT) as an adjuvant chemotherapy for hepatic resection offered no evidence of a potential benefit and the overall survival rates appeared to be worse in the treatment group. The authors suggested that the adverse effects of UFT on liver function were responsible for the poor survival rates seen in the treatment group. Some agents appear promising in terms of safety; however, the effects of these agents remain to be confirmed. ${ }^{68,69}$ The prevention of a recurrence of $\mathrm{HCC}$, or tertiary prevention, is currently one of the most challenging tasks in hepatology.

\section{REFERENCES}

1. Parkin DM, Bray F, Ferlay J, Pisani P. Estimating the world cancer burden: Globocan 2000. Int J Cancer 2001;94:153-156.

2. Omata M, Ashcavai M, Liew CT, Peters RL. Hepatocellular carcinoma in the U.S.A., etiologic considerations. Localization of hepatitis B antigens. Gastroenterology 1979;76:279-287.

3. Sherlock S. Viruses and hepatocellular carcinoma. Gut 1994;35:828-832.

4. Bosch FX, Ribes J, Diaz M, Cleries R. Primary liver cancer: worldwide incidence and trends. Gastroenterology 2004;127:S5-S16.

5. Kew MC, Yu MC, Kedda MA, Coppin A, Sarkin A, Hodkinson $J$. The relative roles of hepatitis $B$ and $C$ viruses in the etiology of hepatocellular carcinoma in southern African blacks. Gastroenterology 1997;112:184-187.

6. Calle EE, Rodriguez C, Walker-Thurmond K, Thun MJ. Overweight, obesity, and mortality from cancer in a prospectively studied cohort of U.S. adults. N Engl J Med 2003;348:1625-1638.

7. Pybus OG, Charleston MA, Gupta S, Rambaut A, Holmes EC, Harvey PH. The epidemic behavior of the hepatitis $\mathrm{C}$ virus. Science 2001;292:2323-2325.

8. Strader DB, Wright T, Thomas DL, Seeff LB. Diagnosis, management, and treatment of hepatitis C. Hepatology 2004;39:1147-1171.

9. Frank C, Mohamed MK, Strickland GT, Lavanchy D, Arthur RR, Magder LS, et al. The role of parenteral antischistosomal therapy in the spread of hepatitis $C$ virus in Egypt. Lancet 2000;355:887-891.

10. Okuda K, Fujimoto I, Hanai A, Urano Y. Changing incidence of hepatocellular carcinoma in Japan. Cancer Res 1987;47:4967-4972.

11. Omata M, Yoshida H, Shiratori Y. Prevention of hepatocellular carcinoma and its recurrence in chronic hepatitis $\mathrm{C}$ patients by 
interferon therapy. Clin Gastroenterol Hepatol 2005;3:S141-143.

12. Tanaka Y, Hanada K, Mizokami M, Yeo AE, Shih JW, Gojobori $\mathrm{T}$, et al. Inaugural Article: A comparison of the molecular clock of hepatitis C virus in the United States and Japan predicts that hepatocellular carcinoma incidence in the United States will increase over the next two decades. Proc Natl Acad Sci USA 2002;99:15584-15589.

13. El-Serag HB, Davila JA, Petersen NJ, McGlynn KA. The continuing increase in the incidence of hepatocellular carcinoma in the United States: an update. Ann Intern Med 2003;139:817-823.

14. Simonetti RG, Camma C, Fiorello F, Cottone M, Rapicetta M, Marino L, et al. Hepatitis $\mathrm{C}$ virus infection as a risk factor for hepatocellular carcinoma in patients with cirrhosis. A case-control study. Ann Intern Med 1992;116:97-102.

15. Colombo M, de Franchis R, Del Ninno E, Sangiovanni A, De Fazio C, Tommasini M, et al. Hepatocellular carcinoma in Italian patients with cirrhosis. N Engl J Med 1991;325:675-680.

16. Lok AS, Seeff LB, Morgan TR, di Bisceglie AM, Sterling RK, Curto TM, et al. Incidence of hepatocellular carcinoma and associated risk factors in hepatitis C-related advanced liver disease. Gastroenterology 2009;136:138-148.

17. Yoshida H, Shiratori Y, Moriyama M, Arakawa Y, Ide T, Sata $\mathrm{M}$, et al. Interferon therapy reduces the risk for hepatocellular carcinoma: national surveillance program of cirrhotic and noncirrhotic patients with chronic hepatitis C in Japan. IHIT Study Group. Inhibition of Hepatocarcinogenesis by Interferon Therapy. Ann Intern Med 1999;131:174-181.

18. Nishiguchi S, Kuroki T, Nakatani S, Morimoto H, Takeda T, Nakajima S, et al. Randomised trial of effects of interferonalpha on incidence of hepatocellular carcinoma in chronic active hepatitis C with cirrhosis. Lancet 1995;346:1051-1055.

19. Shiratori Y, Imazeki F, Moriyama M, Yano M, Arakawa Y, et al. Histologic improvement of fibrosis in patients with hepatitis $\mathrm{C}$ who have sustained response to interferon therapy. Ann Intern Med 2000;132:517-524.

20. Manns MP, McHutchison JG, Gordon SC, Rustgi VK, Shiffman $\mathrm{M}$, Reindollar R, et al. Peginterferon alfa-2b plus ribavirin compared with interferon alfa-2b plus ribavirin for initial treatment of chronic hepatitis $\mathrm{C}$ : a randomised trial. Lancet 2001;358:958-965.

21. Fried MW, Shiffman ML, Reddy KR, Smith C, Marinos G, Goncales FL, et al. Peginterferon alfa-2a plus ribavirin for chronic hepatitis C virus infection. N Engl J Med 2002;347:975-982.

22. Yoshizawa $\mathrm{H}$. Hepatocellular carcinoma associated with hepatitis $\mathrm{C}$ virus infection in Japan: projection to other countries in the foreseeable future. Oncology 2002;62 Suppl 1:8-17.

23. Kiyosawa K, Umemura T, Ichijo T, Matsumoto A, Yoshizawa K, Gad A, et al. Hepatocellular carcinoma: recent trends in Japan. Gastroenterology 2004;127:S17-26.

24. Beasley RP, Hwang LY, Lin CC, Chien CS. Hepatocellular carcinoma and hepatitis B virus. A prospective study of 22707 men in Taiwan. Lancet 1981;2:1129-1133.

25. Fattovich G, Giustina G, Schalm SW, Hadziyannis S, SanchezTapias J, Almasio P, et al. Occurrence of hepatocellular carcinoma and decompensation in western European patients with cirrhosis type B. The EUROHEP Study Group on Hepatitis B Virus and Cirrhosis. Hepatology 1995;21:77-82.

26. Tsukuma H, Hiyama T, Tanaka S, Nakao M, Yabuuchi T, Kitamura $\mathrm{T}$, et al. Risk factors for hepatocellular carcinoma among patients with chronic liver disease. N Engl J Med 1993;328:1797-1801.

27. Chen CJ, Yang HI, Su J, Jen CL, You SL, Lu SN, et al. Risk of hepatocellular carcinoma across a biological gradient of serum hepatitis B virus DNA level. JAMA 2006;295:65-73.

28. Takano S, Yokosuka O, Imazeki F, Tagawa M, Omata M. Incidence of hepatocellular carcinoma in chronic hepatitis B and C: a prospective study of 251 patients. Hepatology 1995;21:650-655.

29. Kato Y, Nakata K, Omagari K, Furukawa R, Kusumoto Y, Mori I, et al. Risk of hepatocellular carcinoma in patients with cirrhosis in Japan. Analysis of infectious hepatitis viruses. Cancer 1994;74:2234-2238.

30. Liang TJ, Jeffers LJ, Reddy KR, De Medina M, Parker IT, Cheinquer $\mathrm{H}$, et al. Viral pathogenesis of hepatocellular carcinoma in the United States. Hepatology 1993;18:1326-1333.

31. Tanaka K, Hirohata T, Takeshita S, Hirohata I, Koga S, Sugimachi K, et al. Hepatitis B virus, cigarette smoking and alcohol consumption in the development of hepatocellular carcinoma: a case-control study in Fukuoka, Japan. Int J Cancer 1992;51:509-514.

32. Donato F, Tagger A, Gelatti U, Parrinello G, Boffetta P, Albertini A, et al. Alcohol and hepatocellular carcinoma: the effect of lifetime intake and hepatitis virus infections in men and women. Am J Epidemiol 2002;155:323-331.

33. Kuper H, Tzonou A, Kaklamani E, Hsieh CC, Lagiou P, Adami $\mathrm{HO}$, et al. Tobacco smoking, alcohol consumption and their interaction in the causation of hepatocellular carcinoma. Int $\mathrm{J}$ Cancer 2000;85:498-502.

34. Schoniger-Hekele M, Muller C, Kutilek M, Oesterreicher C, Ferenci P, Gangl A. Hepatocellular carcinoma in Austria: aetiological and clinical characteristics at presentation. Eur $\mathrm{J}$ Gastroenterol Hepatol 2000;12:941-948.

35. El-Serag HB, Mason AC. Risk factors for the rising rates of primary liver cancer in the United States. Arch Intern Med 2000; 160:3227-3230

36. Bugianesi E, Leone N, Vanni E, Marchesini G, Brunello F, Carucci P, et al. Expanding the natural history of nonalcoholic steatohepatitis: from cryptogenic cirrhosis to hepatocellular carcinoma. Gastroenterology 2002;123:134-140.

37. Shimada M, Hashimoto E, Taniai M, Hasegawa K, Okuda H, Hayashi N, et al. Hepatocellular carcinoma in patients with nonalcoholic steatohepatitis. J Hepatol 2002;37:154-160.

38. Castera L, Vergniol J, Foucher J, Le Bail B, Chanteloup E, Haaser $\mathrm{M}$, et al. Prospective comparison of transient elastography, Fibrotest, APRI, and liver biopsy for the assessment of fibrosis in chronic hepatitis C. Gastroenterology 2005;128:343-350.

39. Ziol M, Handra-Luca A, Kettaneh A, Christidis C, Mal F, Kazemi F, et al. Noninvasive assessment of liver fibrosis by measurement of stiffness in patients with chronic hepatitis C. Hepatology 2005;41:48-54.

40. Sandrin L, Fourquet B, Hasquenoph JM, Yon S, Fournier $\mathrm{C}$, Mal F, et al. Transient elastography: a new noninvasive method for assessment of hepatic fibrosis. Ultrasound Med Biol 2003;29:1705-1713.

41. Foucher J, Chanteloup E, Vergniol J, Castera L, Le Bail B, Adhoute X, et al. Diagnosis of cirrhosis by transient elastography (FibroScan): a prospective study. Gut 2006;55:403-408.

42. Ganne-Carrie N, Ziol M, de Ledinghen V, Douvin C, Marcellin $\mathrm{P}$, Castera L, et al. Accuracy of liver stiffness measurement for the diagnosis of cirrhosis in patients with chronic liver diseases. Hepatology 2006;44:1511-1517.

43. Masuzaki R, Tateishi R, Yoshida H, Yoshida H, Sato S, Kato N, et al. Risk assessment of hepatocellular carcinoma in chronic hepatitis C patients by transient elastography. J Clin Gastroenterol 2008;42:839-843.

44. Masuzaki R, Tateishi R, Yoshida H, Goto E, Sato T, Ohki T, et al. Prospective risk assessment for hepatocellular carcinoma development in patients with chronic hepatitis $\mathrm{C}$ by transient elastography. Hepatology 2009;49:1954-1961.

45. Imbert-Bismut F, Ratziu V, Pieroni L, Charlotte F, Benhamou Y, Poynard T. Biochemical markers of liver fibrosis in patients with hepatitis C virus infection: a prospective study. Lancet 2001;357:1069-1075.

46. Wai CT, Greenson JK, Fontana RJ, Kalbfleisch JD, Marrero JA, Conjeevaram HS, et al. A simple noninvasive index can predict both significant fibrosis and cirrhosis in patients with chronic hepatitis C. Hepatology 2003;38:518-526.

47. Sherman M, Peltekian KM, Lee C. Screening for hepatocellular carcinoma in chronic carriers of hepatitis B virus: incidence and prevalence of hepatocellular carcinoma in a North American urban population. Hepatology 1995;22:432-438.

48. Pateron D, Ganne N, Trinchet JC, Aurousseau MH, Mal F, Meicler C, et al. Prospective study of screening for hepatocellular carcinoma in Caucasian patients with cirrhosis. J Hepatol 1994;20:65-71.

49. Bolondi L, Sofia S, Siringo S, Gaiani S, Casali A, Zironi G, et al. Surveillance programme of cirrhotic patients for early diagnosis and treatment of hepatocellular carcinoma: a cost effectiveness analysis. Gut 2001;48:251-259.

50. Cottone M, Turri M, Caltagirone M, Parisi P, Orlando A, Fiorentino G, et al. Screening for hepatocellular carcinoma in patients with Child's A cirrhosis: an 8-year prospective study by ultrasound and alphafetoprotein. J Hepatol 1994;21:1029-1034. 
51. Zhang BH, Yang BH, Tang ZY. Randomized controlled trial of screening for hepatocellular carcinoma. J Cancer Res Clin Oncol 2004; 130:417-422.

52. Trevisani F, Cantarini MC, Labate AM, De Notariis S, Rapaccini G, Farinati F, et al. Surveillance for hepatocellular carcinoma in elderly Italian patients with cirrhosis: effects on cancer staging and patient survival. Am J Gastroenterol 2004;99:1470-1476.

53. Shiina S, Teratani T, Obi S, Sato S, Tateishi R, Fujishima T, et al. A randomized controlled trial of radiofrequency ablation with ethanol injection for small hepatocellular carcinoma. Gastroenterology 2005;129:122-130.

54. Lin SM, Lin CJ, Lin CC, Hsu CW, Chen YC. Radiofrequency ablation improves prognosis compared with ethanol injection for hepatocellular carcinoma $<$ or $=4 \mathrm{~cm}$. Gastroenterology 2004;127:1714-1723.

55. Shiina S, Tateishi R, Arano T, Uchino K, Enooku K, Nakagawa $\mathrm{H}$, et al. Radiofrequency ablation for hepatocellular carcinoma: 10-Year outcome and prognostic factors. J Gastroenterol 2012;107:569-577.

56. Llovet JM, Schwartz M, Mazzaferro V. Resection and liver transplantation for hepatocellular carcinoma. Semin Liver Dis 2005;25:181-200.

57. Llovet JM, Burroughs A, Bruix J. Hepatocellular carcinoma. Lancet 2003;362:1907-1917.

58. Balsells J, Charco R, Lazaro JL, Murio E, Vargas V, Allende $\mathrm{E}$, et al. Resection of hepatocellular carcinoma in patients with cirrhosis. Br J Surg 1996;83:758-761.

59. Iwatsuki S, Starzl TE, Sheahan DG, Yokoyama I, Demetris AJ, Todo S, et al. Hepatic resection versus transplantation for hepatocellular carcinoma. Ann Surg 1991;214:221-228; discussion 228-229.

60. Pichlmayr R, Weimann A, Oldhafer KJ, Schlitt HJ, Tusch G, Raab R. Appraisal of transplantation for malignant tumours of the liver with special reference to early stage hepatocellular carcinoma. Eur J Surg Oncol 1998;24:60-67.

61. Mazzaferro V, Regalia E, Doci R, Andreola S, Pulvirenti A, Bozzetti F, et al. Liver transplantation for the treatment of small hepatocellular carcinomas in patients with cirrhosis. N Engl J Med
1996;334:693-699.

62. Sasaki Y, Yamada T, Tanaka H, Ohigashi H, Eguchi H, Yano M, et al. Risk of recurrence in a long-term follow-up after surgery in 417 patients with hepatitis B- or hepatitis C-related hepatocellular carcinoma. Ann Surg 2006;244:771-780.

63. Poon RT, Fan ST, Lo CM, Liu CL, Wong J. Long-term survival and pattern of recurrence after resection of small hepatocellular carcinoma in patients with preserved liver function: implications for a strategy of salvage transplantation. Ann Surg 2002;235:373-382.

64. Sakon M, Umeshita K, Nagano H, Eguchi H, Kishimoto S, Miyamoto A, et al. Clinical significance of hepatic resection in hepatocellular carcinoma: analysis by disease-free survival curves. Arch Surg 2000;135:1456-1459.

65. Kubo S, Nishiguchi S, Hirohashi K, Tanaka H, Shuto T, Yamazaki $\mathrm{O}$, et al. Effects of long-term postoperative interferon-alpha therapy on intrahepatic recurrence after resection of hepatitis $\mathrm{C}$ virus-related hepatocellular carcinoma. A randomized, controlled trial. Ann Intern Med 2001;134:963-967.

66. Shiratori Y, Shiina S, Teratani T, Imamura M, Obi S, Sato S, et al. Interferon therapy after tumor ablation improves prognosis in patients with hepatocellular carcinoma associated with hepatitis $\mathrm{C}$ virus. Ann Intern Med 2003;138:299-306.

67. Hasegawa K, Takayama T, Ijichi M, Matsuyama Y, Imamura H, Sano K, et al. Uracil-tegafur as an adjuvant for hepatocellular carcinoma: a randomized trial. Hepatology 2006;44:891-895.

68. Muto Y, Moriwaki H, Ninomiya M, Adachi S, Saito A, Takasaki KT, et al. Prevention of second primary tumors by an acyclic retinoid, polyprenoic acid, in patients with hepatocellular carcinoma. Hepatoma Prevention Study Group. N Engl J Med 1996;334:1561-1567.

69. Habu D, Shiomi S, Tamori A, Takeda T, Tanaka T, Kubo S, et al. Role of vitamin K2 in the development of hepatocellular carcinoma in women with viral cirrhosis of the liver. JAMA 2004;292:358-361. 